\title{
Creating accessible active sites in hierarchical MFI zeolites for low-temperature acid catalysis
}

\author{
Andrea Erigoni[a], Stephanie H. Newland ${ }^{[b]}$, Geo Paull ${ }^{[a]}$, Leonardo Marchese ${ }^{[a]}$, Robert Raja ${ }^{[b]}$ and \\ Enrica Gianotti*[a]
}

\begin{abstract}
A versatile desilication design strategy for the creation of hierarchical H-ZSM-5 catalysts with different Si/Al ratio has been demonstrated. The nature, strength and the accessibility of the acid sites after the alkaline treatment was elucidated by employing a range of physico-chemical characterization tools; notably probebased FTIR spectroscopy along with SS MAS-NMR. In addition, structural and textural properties of the hierarchical zeolites were also explored and compared to their corresponding microporous analogues. CO was used to probe the acidic properties of the hierarchical zeolites with the concomitant deployment of a bulky molecular probe, 2,4,6-trimethylpyridine (collidine), which is too large to access the micropores, to specifically investigate the enhanced accessibility of the active sites. The hierarchical zeolites were evaluated in the industrially relevant, acid-catalyzed Beckmann rearrangement of cyclohexanone oxime to $\varepsilon$-caprolactam, the precursor for Nylon-6, in liquid phase and at low-temperatures. The catalytic findings with the hierarchical catalysts reveal a significant enhancement in the production of $\varepsilon$-caprolactam, compared with the parent microporous H-ZSM- 5 zeolite, thereby highlighting the merits of our design approach in facilitating enhanced diffusion and masstransfer.
\end{abstract}

\section{Introduction}

Zeolites and zeotypes materials have been widely applied to heterogeneous catalysis, adsorption and ion exchange. The unique features of these materials are related to their tunable surface properties as well as their crystalline microporous structure, which facilitates shape selectivity towards reactants and products. However, the limitations afforded by microporous channels impose significant diffusion constraints, especially for low-temperature acid catalysis. Recently, hierarchical zeolites, which combine micro and mesopores in a multilevel pore network, strongly emerged as novel materials for catalytic applications to overcome typical drawbacks of traditional microporous materials such as poor mass-transfer and hindered diffusion. ${ }^{[1,2]}$ Direct benefits of the incorporation of micropores

[a] Mr A. Erigoni, Dr G. Paul, Prof. L. Marchese and Prof. E. Gianott Department of Science and Technological Innovation, Università del Piemonte Orientale, Viale T. Michel 11, 15121 Alessandria, Italy. E-mail: enrica.gianotti@uniupo.it

[b] Dr S. H. Newland, Prof. R. Raja School of Chemistry, Faculty of Natural and Environmental Sciences University of Southampton, SO17 1BJ, U.K.

Supporting information for this article is given via a link at the end of the document

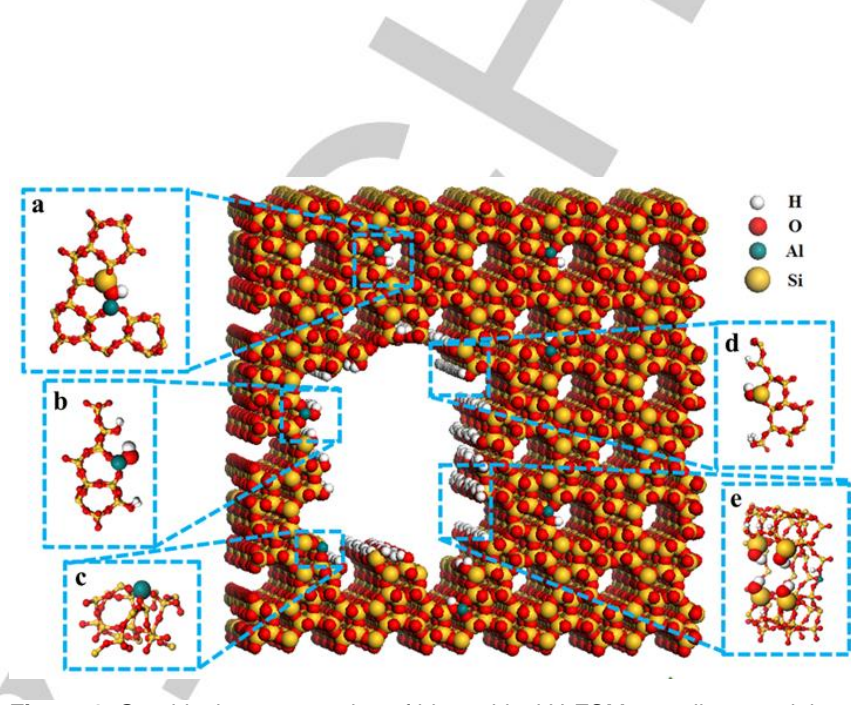

Figure 1. Graphical representation of hierarchical H-ZSM-5 zeolite containing different acid sites. (a): Brønsted acid sites; (b) extra-framework aluminols; (c) Lewis acid sites; (d) isolated silanols; (e) nest silanols.

and mesopores within a single porous architecture have been demonstrated in key catalytic processes for petroleum refining, catalytic cracking of hydrocarbons, isomerization and fine chemical applications. ${ }^{[3-5]}$ Many synthetic strategies (e.g. bottomup and top-down approaches and zeolite recrystallization) have been explored for the formation of hierarchical zeolites, which contain interconnected micro- and mesopores, in prospect of possible industrial applications..$^{[6-10]}$ Among the different synthetic procedures that can be followed to produce hierarchical zeolites, the top-down routes based on post-synthetic treatments in acid or alkali solutions are widely used, owing to favourable HSE (health-safety-environment) considerations and low production costs. ${ }^{[6,11,12]}$ This method partially extracts the framework constituents ( $\mathrm{Al}$ or $\mathrm{Si}$ ) and depending on type of treatment, it can be classified into dealumination or desilication. In particular, under optimized conditions (acid or alkali sources, concentration, temperature and contact time), desilication in alkali media can be extensively used to create mesopores in zeolites, whilst preserving the crystalline structure almost entirely with a decreasing of the $\mathrm{Si} / \mathrm{Al}$ ratio. In addition a clear advantage of this method in access-limited and diffusion-constrained reactions is that the produced mesopores are interconnected and accessible from the external surface of the zeolite crystal. ${ }^{[13,14]}$ The desilication methodology was for the first time applied in 1960 to a mordenite zeolite, which upon the alkali treatment displayed high crystallinity with enhanced benzene adsorption capacity. ${ }^{[15]}$ Nevertheless, for several decades, such type of post-synthetic treatments did not find great scientific interest due to an incomplete understanding of mesopore formation mechanism. Recently, explicit evidence of mesopore formation in ZSM-5 crystals by $\mathrm{NaOH}$ treatment has been reported, ${ }^{[16]}$ which opens up promising potential for acid catalysis with bulky substrates. Currently, desilication is the most widely used method to 
introduce disordered mesopores into microporous zeolite frameworks and it is accepted that the long-range order and Brønsted acidity of the zeolites is retained upon alkaline treatment. ${ }^{[17]}$ The hierarchical zeolites have shown enhanced catalytic performances with respect to the microporous analogues in diffusion-constrained reactions or those carried out in the liquid-phase at low temperatures. ${ }^{[11,18]}$ In the present study, a post-synthetic desilication strategy in alkali media was followed to achieve hierarchical H-ZSM-5 (Fig.1), starting from parent MFI zeolites with different Si/Al ratio. H-ZSM-5 is a wellknown microporous zeolite with a cross-section of straight channels $(5.1 \AA$ x $5.5 \AA)$ intersected by zig-zag channels $(5.3 \AA$ $x 5.6 \AA$ ) and it is widely used as a heterogeneous acid catalyst in a large number of reactions. ${ }^{[19,20]}$ In H-ZSM-5 microporous zeolites, different types of silanol groups are present, external and internal $\mathrm{Si}-\mathrm{OH}$ and nest $\mathrm{Si}-\mathrm{OH}$, together with stronger Si$\mathrm{OH}-\mathrm{Al}$ Brønsted sites. The alkali treatment adopted to produce hierarchical $\mathrm{H}$-ZSM-5 can modify these $\mathrm{OH}$ sites, in terms of their localization, concentration and acid strength. ${ }^{[2]}$ To get information on the nature, strength and accessibility of the acid sites after the alkaline treatment, a detailed physico-chemical characterization using FTIR spectroscopy of adsorbed molecules together with SS MAS-NMR was performed. In addition, structural and textural properties of the hierarchical zeolites were also explored by means of XRD and volumetric analyses. FTIR spectroscopy of adsorbed probe molecules is a powerful tool for systematic studies of acidity of hierarchical zeolites providing information on the influence of desilication conditions on location, content, acid strength and accessibility of both Brønsted and Lewis sites. ${ }^{[21-23]}$ In this study, CO was used to assess the acidic properties of the hierarchical zeolites and a larger basic molecule such as 2,4,6-trimethylpyridine (collidine), which cannot assess the micropores, was used to get information on the enhanced accessibility to the active sites. The hierarchical H-ZSM-5 zeolites were evaluated in the industrially relevant acid-catalyzed Beckmann rearrangement of cyclohexanone oxime to $\varepsilon$-caprolactam in the liquid-phase and at low temperatures, specifically to avoid the formation of large molecular weight condensation products and other by-products that are generated in the conventional gas-phase process. ${ }^{[24]}$ Compared to the vapor-phase Beckmann rearrangement, which is usually carried out at temperatures in excess of $275^{\circ} \mathrm{C}$, the liquid-phase approach that we outline in this article provides a viable alternative for minimizing the catalyst deactivation, ${ }^{[25]}$ through the associated production of tars, as highlighted above. The use of heterogeneous acid catalysts for Beckmann rearrangement of cyclohexanone oxime is a highly desirable alternative to the industrial Raschig process (Fig.S1 A in the SI).
In fact, an industrial process based on high-silica microporous $\mathrm{MFI}$ catalyst has been developed in vapour-phase at $350-400^{\circ} \mathrm{C}$ for the commercial production of $\varepsilon$-caprolactam in 2007 (Fig. S1 $\mathrm{B}$ in the SI). ${ }^{26]}$ Nevertheless, the specific role of active sites of different acid strength in zeolites for Beckmann rearrangement is still under debate. ${ }^{[27]}$ In particular, the role of strong Brønsted acid sites and weak acid sites such as silanol groups and eventually their synergy has to be considered for effective structure-property correlation and mechanistic insights. From early studies, nest silanols (four neighbouring silanol groups, Fig. $\mathrm{S} 2 \mathrm{~B}$ in the SI) play a key role in the vapor-phase Beckmann rearrangement, ${ }^{[26,28]}$ while in the liquid phase; the Brønsted sites (Si-OH-Al groups, Fig S2 A in the SI) are the active centers. ${ }^{[25]}$ By combining the textural and structural properties of the hierarchical zeolites with detailed spectroscopic probe-based characterization, unique insights into the role of solid acid sites that are effective for low-temperature Beckmann rearrangement will be revealed.

\section{Results and Discussion}

The hierarchical H-ZSM-5 zeolites with different Si/Al ratio (labelled $30 \mathrm{H}$ and $80 \mathrm{H}$ ) were obtained by top-down route using an alkaline treatment $(0.2 \mathrm{M} \mathrm{NaOH}$ solution) of the parent zeolites (labelled 30P and 80P). It is known that desilication method can improve the defect concentration within the framework together with the introduction of intracrystalline mesoporosity. To assess the porosity, the structural changes and the nature, accessibility and strength of the acid sites, a detailed physico-chemical characterization was performed by means of structural, volumetric and spectroscopic analysis. The desilication in alkali media used to introduce mesopores into microporous zeolites normally increases the defect concentration and amorphization of the framework. To control the crystal structure of the hierarchical materials obtained by alkaline treatment, X-ray diffraction (XRD) analysis was performed (Fig.2A). The alkaline alkaline-treated samples showed the typical diffraction pattern of the MFI structure, indicating that the long-range order was preserved in the hierarchical zeolites; only a slight decrease in the peak intensities is observed. The ICP analysis evidenced a slightly decrease in the $\mathrm{Si}$ content along with an increase of the $\mathrm{Al}$ concentration in the alkali treated catalysts as expected (Table 1).

Table 1. ICP chemical analysis of parent and hierarchical zeolites.

\begin{tabular}{|c|c|c|c|c|}
\hline Materials & Si / wt \% & $\mathrm{Al} / \mathrm{wt} \%$ & $\mathrm{Si} / \mathrm{Al}$ & $\mathrm{SiO}_{2} / \mathrm{Al}_{2} \mathrm{O}_{3}$ \\
\hline $80 \mathrm{P}$ & 43.88 & 0.92 & 48 & 80 \\
\hline $80 \mathrm{H}$ & 39.55 & 1.87 & 21 & 36 \\
\hline $30 P$ & 40.80 & 2.28 & 18 & 30 \\
\hline $30 \mathrm{H}$ & 38.32 & 3.59 & 10.6 & 18 \\
\hline
\end{tabular}



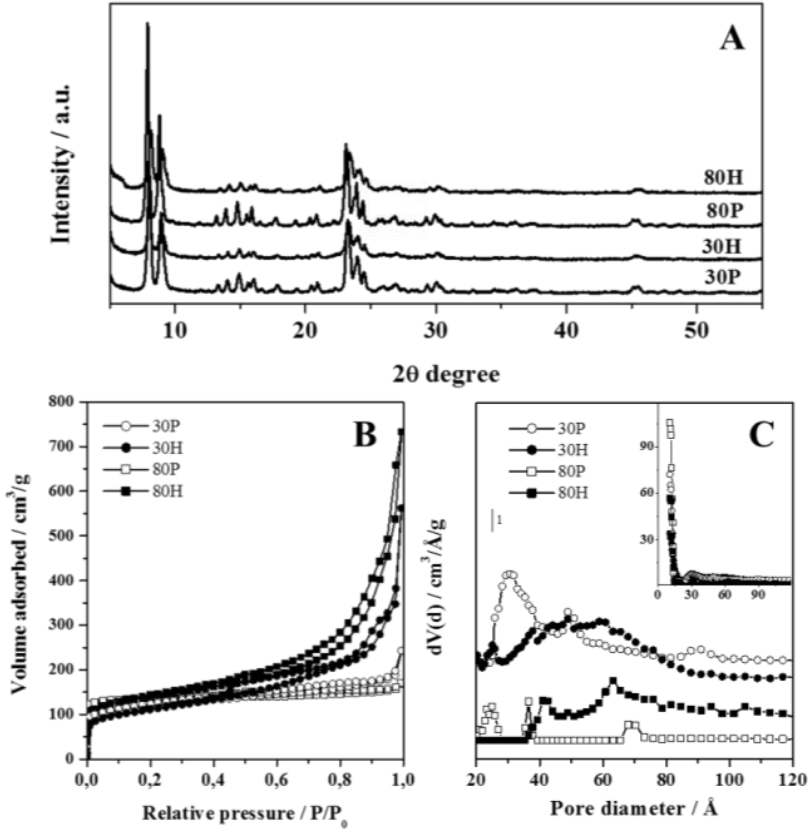

Figure 2. A: XRD pattern of parent and hierarchical calcined HZSM-5. B: $\mathrm{N}_{2}$ adsorption/desorption isotherms at $77 \mathrm{~K}$ of parent and hierarchical zeolites. C: Pore size distribution of the zeolites in the mesopores range. In the inset, the pore size distribution in the micropore range is reported.

The introduction of mesoporosity upon alkaline treatment in $\mathrm{H}$ ZSM-5 zeolites is evidenced by $\mathrm{N}_{2}$ adsorption/desorption analysis at $77 \mathrm{~K}$ (Fig. 2B). The isotherms of the parent samples show a profile typical of microporous materials (type I isotherm), on the contrary an enhanced $\mathrm{N}_{2}$ uptake at intermediate and relative high pressures, with a profile typical of mesoporous materials (type IV isotherm) was observed for the hierarchical catalysts. The desorption branch of the isotherms were analysed by means of the NLDFT (non-localized density functional theory) method to obtain the pore-size distributions of the materials (Fig. $2 \mathrm{C}$ ). The pore size distribution of the parent zeolites evidenced that beside the predominant fraction of micropores, some mesoporosity is also observed. In particular the $80 \mathrm{P}$ sample, show mesopores at about $25 \AA$, while $30 \mathrm{P}$ centered at ca. $30 \AA$, possibly due to some intercrystalline porosity between small crystals. ${ }^{[29]}$ The quantification of the specific pore volumes and surface areas via the NLDFT method is summarized in Table 2. Upon the alkaline treatment, a broad mesopore distribution centred at about $60 \AA$ for both hierarchical samples is visible together with an enhancement of the mesopore volume $\left(\mathrm{V}_{\text {meso }}\right)$ and a reduction of the micropores volume $\left(\mathrm{V}_{\text {micro }}\right)$. An enhancement up to $87-88 \%$ of the total volume is observed in the hierarchical zeolites. The total surface area $\left(\mathrm{S}_{\mathrm{DFT}}\right)$ decreases from $965 \mathrm{~m}^{2} / \mathrm{g}$ to $731 \mathrm{~m}^{2} / \mathrm{g}$ and from $731 \mathrm{~m}^{2} / \mathrm{g}$ to $488 \mathrm{~m}^{2} / \mathrm{g} 80 \mathrm{P}$ and $30 \mathrm{P}$ samples respectively (trend also confirmed using BET method). This appears reasonable considering that the desilication should perturb the micropore network in favour of the mesopores formation. Indeed, in Fig. $3 \mathrm{C}$-inset, it is clear that the signal related to the micropores is weaker in the hierarchical samples than in the parent ones: in fact micropores area $\left(\mathrm{S}_{\text {micro }}\right)$ decreases from $946 \mathrm{~m}^{2} / \mathrm{g}$ to $516 \mathrm{~m}^{2} / \mathrm{g}$ and from $629 \mathrm{~m}^{2} / \mathrm{g}$ to 287 $\mathrm{m}^{2} / \mathrm{g}$ for $80 \mathrm{P}$ and $30 \mathrm{P}$ samples respectively, while the mesopores area $\left(\mathrm{S}_{\text {meso }}\right)$ greatly increases reaching 215 and 201 $\mathrm{m}^{2} / \mathrm{g}$ for $80 \mathrm{H}$ and $30 \mathrm{H}$ samples respectively.

Due to the high heterogeneity of the hydroxyl centres possibly present in hierarchical HZSM-5 zeolites and in order to assess the impact of the post-synthetic desilication on their acidic properties of hierarchical zeolites, FTIR spectroscopy of adsorbed probe molecules coupled with ${ }^{1} \mathrm{H}$ MAS-NMR spectroscopy was used.

The effect of the alkaline treatment on hierarchical HZSM-5 is visible in the $\mathrm{O}-\mathrm{H}$ stretching region of the FTIR spectra (Fig. $3 \mathrm{~A}$ ); the samples have been treated at $250{ }^{\circ} \mathrm{C}$ and $500^{\circ} \mathrm{C}$ in vacuum The alkaline-treated zeolites $(30 \mathrm{H}$ and $80 \mathrm{H})$ show an increasing of the signal due to isolated $\mathrm{Si}-\mathrm{OH}$ groups $\left(3745 \mathrm{~cm}^{-1}\right)$ with respect to the parent zeolites (30P and $80 \mathrm{P})$ in agreement with their increased external surface area. On the contrary, a fraction of the bridging $\mathrm{Si}-\mathrm{OH}-\mathrm{Al}$ groups (Brønsted acid sites, BAS), that show a typical band at $3615 \mathrm{~cm}^{-1}$, was lost in the hierarchical catalysts; this effect is particular evident in the low Si/Al catalyst $(30 \mathrm{H})$. In addition, a band at $3665 \mathrm{~cm}^{-1}$ due to the stretching

Table 2 - Textural properties of parent and hierarchical H-ZSM-5 zeolites

\begin{tabular}{|c|c|c|c|c|c|c|c|c|c|}
\hline Materials & $\begin{array}{l}\mathrm{S}_{\mathrm{BET}} \\
\mathrm{m}^{2} / \mathrm{g}\end{array}$ & $\begin{array}{l}\mathrm{S}_{\mathrm{DFT}} \\
\mathrm{m}^{2} / \mathrm{g}\end{array}$ & $\begin{array}{l}S_{\text {micro }} \\
\mathrm{m}^{2} / \mathrm{g}\end{array}$ & $\begin{array}{c}{ }^{\mathrm{a}} \mathrm{S}_{\text {meso }} \\
\mathrm{m}^{2} / \mathrm{g}\end{array}$ & $\begin{array}{c}{ }^{\mathrm{b}} \text { Relative } \\
\text { mesopore } \\
\text { area }\end{array}$ & $\begin{array}{l}V_{\text {tot DFT }} \\
\mathrm{cm}^{3} / \mathrm{g}\end{array}$ & $\begin{array}{l}V_{\text {micro }} \\
\mathrm{cm}^{3} / \mathrm{g}\end{array}$ & $\begin{array}{l}V_{\text {meso }} \\
\mathrm{cm}^{3} / \mathrm{g}\end{array}$ & $\begin{array}{c}{ }^{c} \text { Relative } \\
\text { mesopore } \\
\text { volume }\end{array}$ \\
\hline $30 \mathrm{P}$ & 432 & 731 & 629 & 102 & $14 \%$ & 0.301 & 0.13 & 0.171 & $57 \%$ \\
\hline $30 \mathrm{H}$ & 395 & 488 & 287 & 201 & $41 \%$ & 0.584 & 0.0675 & 0.516 & $88 \%$ \\
\hline $80 \mathrm{P}$ & 544 & 965 & 946 & 19 & $2 \%$ & 0.239 & 0.203 & 0.036 & $15 \%$ \\
\hline $80 \mathrm{H}$ & 500 & 731 & 516 & 215 & $29 \%$ & 0.809 & 0.105 & 0.704 & $87 \%$ \\
\hline
\end{tabular}

${ }^{\mathrm{a}} \mathrm{S}_{\text {meso }}=\mathrm{S}_{\mathrm{DFT}}-\mathrm{S}_{\text {micro }} ;{ }^{\mathrm{b}}$ Relative mesopore area $=\mathrm{S}_{\text {meso }} / \mathrm{S}_{\mathrm{DFT}} \mathrm{x} 100 ;{ }^{\mathrm{c}}$ Relative mesopore volume $=\mathrm{V}_{\text {meso }} / \mathrm{V}_{\text {tot DFT }} \mathrm{x} 100$ 
mode of extra framework $\mathrm{Al}-\mathrm{OH}$ groups was visible in the 30P and $30 \mathrm{H}$ samples. Among all the samples, the $\mathrm{OH}$ population of the high silica parent sample (80P) was most affected by the thermal treatment: in the spectrum of the sample treated at $250{ }^{\circ} \mathrm{C}$, the signal due to the stretching of $\mathrm{Si}-\mathrm{OH}$ groups was broad with a contribution at lower frequency and a large absorption cantered at ca. $3500 \mathrm{~cm}^{-1}$ was present. The peak at $3745 \mathrm{~cm}^{-1}$ was assigned to isolated $\mathrm{Si}-\mathrm{OH}$ groups located on the external surface of the zeolite $\left(\mathrm{SiOH}_{\text {ext }}\right)$, while the broad signal at lower frequencies $\left(3720-3710 \mathrm{~cm}^{-1}\right)$ was attributed to $\mathrm{Si}-\mathrm{OH}$ sites predominantly located inside the zeolite structure $\left(\mathrm{SiOH}_{\text {int }}\right)$. The broad feature at ca. $3500 \mathrm{~cm}^{-1}$ was instead assigned to internally located silanols involved in strong hydrogen bonds, socalled nest silanols $\left(\mathrm{Si}-\mathrm{OH}_{\text {nests }}\right)^{[21,30]}$ This latter feature disappeared after the thermal treatment at high temperature $\left(500^{\circ} \mathrm{C}\right)$ and contemporarily in the low frequency region (inset of Fig. 3A), a signal at ca. $900 \mathrm{~cm}^{-1}$ appears. This signal, which is present in the spectra of the parent and hierarchical zeolites, was assigned to a stretching mode of strained $\mathrm{Si}-\mathrm{O}-\mathrm{Si}$ bridges formed by silanol condensation at high temperature. ${ }^{[31,32]}$ This behaviour provides indirect evidence of the presence of nest silanols, at the operating conditions of the catalytic tests. Thermogravimetric analysis (Fig. S3 in the SI) confirms the condensation of silanols, in fact a weight loss, due to water elimination, is observed at temperature higher than $300^{\circ} \mathrm{C}$.
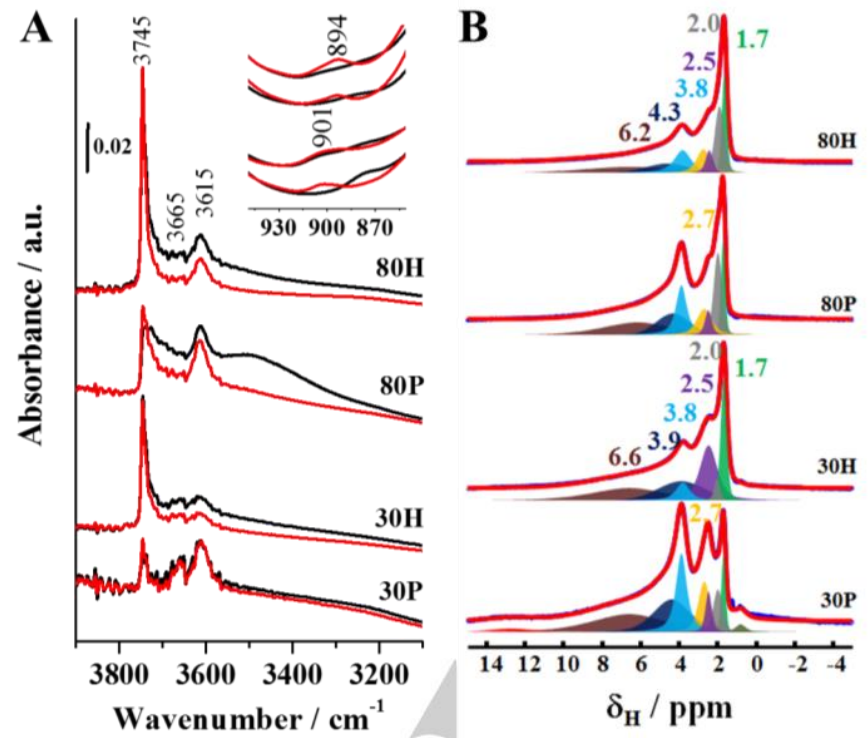

Figure 3. A: FTIR spectra in the $\mathrm{O}-\mathrm{H}$ stretching region of parent and hierarchical ZSM-5 thermally treated at $250^{\circ} \mathrm{C}$ (black lines) and at $500{ }^{\circ} \mathrm{C}$ (red lines); in the inset, the FTIR spectra in the stretching region of Si-O-Si constrained bridges. B: ${ }^{1} \mathrm{H}$ MAS NMR spectra recorded using a MAS rate of $15 \mathrm{kHz}$ after outgassing the catalysts at $250{ }^{\circ} \mathrm{C}$. Experimental and deconvoluted spectra with individual contribution from each ${ }^{1} \mathrm{H}$ sites are reported for each samples.

Together with FTIR spectra, ${ }^{1} \mathrm{H}$ MAS NMR spectroscopy provided direct information about the different proton sites present in the hierarchical zeolites (Fig. 3B). The proton spectra of parent and hierarchical zeolites (recorded on catalysts treated at $250^{\circ} \mathrm{C}$ ) consist of contributions from isolated external silanols (1.6-1.8 ppm), internal silanols (ca. $2.0 \mathrm{ppm}$ ), hydroxyl units bound to Lewis acid sites (LAS) and extra-framework aluminum species (EFAl) through hydrogen bonding (2.4 - $2.8 \mathrm{ppm})$, Brønsted acid sites (3.8 ppm) and hydrogen bonded hydroxyls $\left(\mathrm{Si}-\mathrm{OH}_{\text {nest }}\right)(4.3 \mathrm{ppm}){ }^{[33-35]}$ In addition, a peak at $0.8 \mathrm{ppm}$ due to isolated $\mathrm{Al}-\mathrm{OH}$ is particularly visible in the $30 \mathrm{P}$ sample. The origin and the attribution of the broad component centred at 6.6 $\mathrm{ppm}$ is not straight forward. It might be due to the proton interaction on the heterogeneous surface of the samples and/or partly from the probe background. Quantitative representations of various protonic species are shown in Table 3 . The desilication treatment produces an increase in the signal intensity of isolated $\mathrm{Si}-\mathrm{OH}$ groups with respect to the parent zeolites and a loss of a fraction of Brønsted acid sites, particularly evident for the low Si/Al ratio zeolite. These features are in agreement with the FTIR data. Moreover, the presence of $\mathrm{H}$-bonded species is also confirmed in all samples and the presence of isolated $\mathrm{Al}-\mathrm{OH}$ species is evidenced only in the low $\mathrm{Si} / \mathrm{Al}$ samples.

The ${ }^{1} \mathrm{H}-{ }^{27} \mathrm{Al}$ TRAPDOR NMR experiment was performed by irradiating $a{ }^{27} \mathrm{Al}$ pulse in the delay $\tau$ period of the spin-echo pulse sequence applied to ${ }^{1} \mathrm{H}$ nuclei. During this experiment, the signals of proton groups, which are strongly coupled to aluminum atoms are suppressed. ${ }^{[36]}$ By subtracting the ${ }^{1} \mathrm{H}-{ }^{27} \mathrm{Al}$ TRAPDOR spectrum from the ${ }^{1} \mathrm{H}$ spin-echo MAS NMR spectrum, information on protonic species in close proximity to aluminium nuclei are obtained (Fig.S4 in the $\mathrm{SI}$ ). The resulting spectra (Fig. 4) of the parent zeolites (30P and 80P), showed signals due to Brønsted acid sites and $\mathrm{H}$-bonded $\mathrm{Al}-\mathrm{OH}$. The spectra of the hierarchical zeolites $(30 \mathrm{H}$ and $80 \mathrm{H})$ had a decrease in the bridging $\mathrm{Si}(\mathrm{OH}) \mathrm{Al}$ groups peak intensity and an increase in the intensity of hydroxyl units bound to Lewis acid sites and extraframework aluminum species through hydrogen

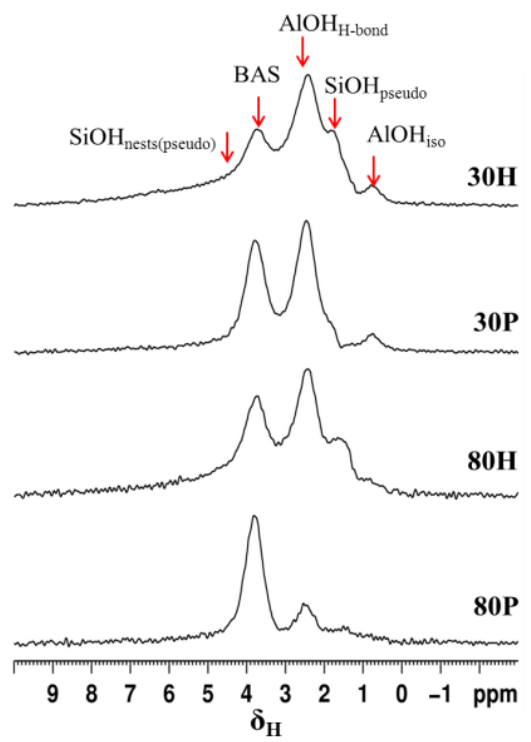

Figure 4. ${ }^{1} \mathrm{H}-{ }^{27} \mathrm{Al}$ TRAPDOR NMR difference spectra of parent and hierarchical zeolites. 
Table 3 - FTIR frequencies and population distribution of protonic species obtained from single-pulse ${ }^{1} \mathrm{H}$ MAS NMR in parent and hierarchical zeolites. Experimental accuracy of $\pm 2 \%$

\begin{tabular}{|c|c|c|c|c|c|c|}
\hline \multirow[t]{2}{*}{$\mathrm{V}_{\mathrm{OH}} / \mathrm{cm}^{-1}$} & \multirow[t]{2}{*}{${ }^{1} \mathrm{H}$ Chemical shift $(\delta) / p p m$} & \multirow[t]{2}{*}{ Assignments } & \multicolumn{4}{|c|}{${ }^{1} \mathrm{H}$ Species (\%) } \\
\hline & & & $30 \mathrm{H}$ & $30 P$ & $80 \mathrm{H}$ & $80 P$ \\
\hline- & $0.5-0.8$ & Isolated $\mathrm{Al}-\mathrm{OH}$ & 2 & 4 & 0 & 0 \\
\hline 3745 & $1.6-1.8$ & $\mathrm{Si}-\mathrm{OH}_{\mathrm{ext}}$ & 12 & 4 & 17 & 6 \\
\hline $3720-3710$ & $1.8-2.0$ & $\mathrm{Si}-\mathrm{OH}_{\mathrm{int}}$ & 17 & 11 & 10 & 11 \\
\hline 3655 & $2.4-2.8$ & $\begin{array}{l}\text { OH bound to Lewis acid and EFAl } \\
\text { species (LAS) through } \mathrm{H} \text {-bond }\end{array}$ & & 16 & 22 & 18 \\
\hline 3615 & 3.8 & Brønsted acid sites (BAS) & 9 & 19 & 13 & 18 \\
\hline ca. 3500 & 4.3 & Strongly $\mathrm{H}$-bonded $\mathrm{Si}-\mathrm{OH}_{\text {nest }}$ & 16 & 17 & 18 & 28 \\
\hline- & 6.6 & $\begin{array}{l}\text { Proton from other components } \\
\text { text for details) }\end{array}$ & 26 & 29 & 20 & 19 \\
\hline
\end{tabular}
silanol nests were detected in hierarchical zeolites (Table 3 and Figure 4). From the ${ }^{1} \mathrm{H}-{ }^{27} \mathrm{Al}$ TRAPDOR NMR studies, it is clear that a substantial amount of isolated silanols and silanol nests in samples $30 \mathrm{H}$ and $80 \mathrm{H}$ were close to aluminium nuclei and these sites can be called pseudo bridging silanols. ${ }^{[37]}$ bonding. Furthermore, signals due to isolated silanols and

removed from the zeolites leading to a lower Si/Al ratio in alkal treated samples, confirmed by ICP analysis.

A

B

Si sites in hierarchical zeolites upon desilication were elucidated by ${ }^{27} \mathrm{Al}$ and ${ }^{29} \mathrm{Si}$ MAS NMR spectroscopy (Fig. $5 \mathrm{~A}$ and $\mathrm{B}$ ). The ${ }^{27} \mathrm{Al}$ MAS NMR spectra showed different contributions in the range 43-59, 28-40 and -1-9 ppm due to four-coordinated ( $\mathrm{Al} \mathrm{IV}^{\mathrm{IV}}$ ), five-coordinated $\left(\mathrm{Al}^{\mathrm{V}}\right)$ and six-coordinated aluminum sites (AlVI), respectively (Fig.5A). ${ }^{[38]}$ The resonances lacked the distinct peaks and shoulders of the second order quadrupolar line shapes, due to the disorder in the aluminum sites, leading to a distribution in the isotropic chemical shift and quadrupolar interaction. The peaks of the tetrahedral ${ }^{27} \mathrm{Al}$ were about $20 \mathrm{ppm}$ wide, which are larger than those typically observed in spectra of highly crystalline zeolites ${ }^{[39]}$ and indicate a large spread of Al-O$\mathrm{Si}$ angles in samples. The quantitative distributions of ${ }^{27} \mathrm{Al}$ sites are shown in Table 4. In general, parent zeolites (30P and 80P) show higher concentration of tetrahedral Al. However, minor fractions of octahedral aluminum sites were also seen. The influence of alkali treatment substantially changes the ${ }^{27} \mathrm{Al}$ site distributions, in fact, higher amount of six coordinated and significant amount of five coordinated aluminum sites are formed at the expense of AlV sites in the hierarchical zeolites.

The ${ }^{29} \mathrm{Si}$ MAS NMR spectra of parent and alkali treated samples show $Q^{4}(0 \mathrm{Al}), Q^{4}(1 \mathrm{Al})$ and $\mathrm{Q}^{3}(0 \mathrm{Al})$ sites (Fig. $\left.5 \mathrm{~B}\right)$. There are two crystallographically different $\mathrm{Q}^{4}(\mathrm{OAI})\left[\mathrm{Si}(\mathrm{OSi})_{4}\right]$ silicon sites at $116 \mathrm{ppm}$ and $-112 \mathrm{ppm}, \mathrm{Q}^{4}(1 \mathrm{Al})$ [Si(OSi) ${ }_{3} \mathrm{OAl}$ ] site at $-108 \mathrm{ppm}$ and $\mathrm{Q}^{3}(\mathrm{OAl})\left[\mathrm{Si}(\mathrm{OSi})_{3}(\mathrm{OH})\right]$ site at $-101 \mathrm{ppm}$ are seen in hierarchical zeolites. It is important to note here that, after alkali treatment, the amount of $\mathrm{Q}^{3}(\mathrm{OAl})$ sites has increased compared to parent samples. Besides, a substantial part of the silica are
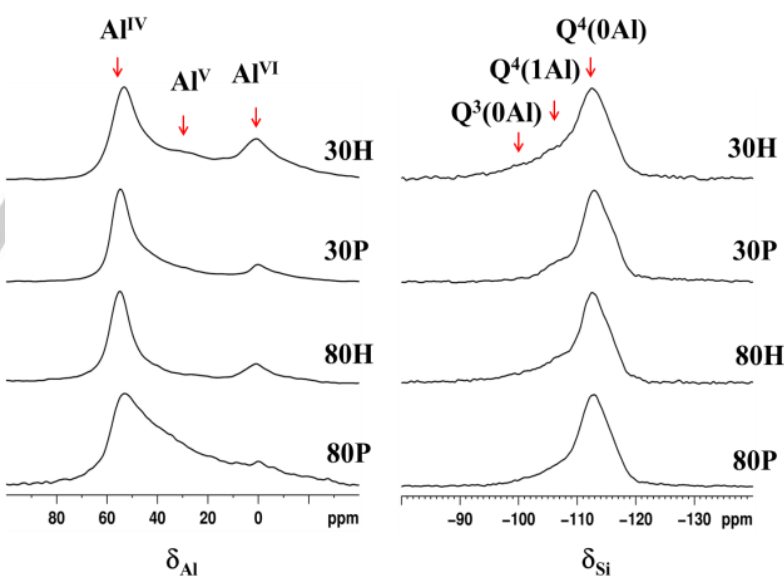

Figure 5. ${ }^{27} \mathrm{Al}$ MAS NMR (A) and ${ }^{29} \mathrm{Si}$ MAS NMR (B) spectra of parent and hierarchical zeolites. 
Table 4. Population distribution of tetrahedral, pentahedral and octahedral ${ }^{27} \mathrm{Al}$ sites in parent and hierarchical zeolites. Experimental accuracy of $\pm 2 \%$.

${ }^{27} \mathrm{Al}$ species / \%

\begin{tabular}{|c|c|c|c|c|c|c|}
\hline \multirow{2}{*}{ Materials } & \multicolumn{2}{|c|}{$\mathrm{Al}^{\mathrm{IV}}$} & \multirow[b]{2}{*}{$\mathrm{Al}^{\mathrm{V}}$} & \multicolumn{3}{|c|}{$\mathrm{Al}^{\mathrm{VI}}$} \\
\hline & $\begin{array}{c}\text { Type } 1 \\
\text { (59 pmm) }\end{array}$ & $\begin{array}{c}\text { Type } 2 \\
\text { (47 ppm) }\end{array}$ & & $\begin{array}{c}\text { Type } 1 \\
\text { (8.6 ppm) }\end{array}$ & $\begin{array}{c}\text { Type } 2 \\
\text { (0.4 ppm) }\end{array}$ & $\begin{array}{c}\text { Type } 3 \\
(-0.3 \text { ppm) }\end{array}$ \\
\hline $80 \mathrm{P}$ & 56 & 42 & 0 & 0 & 0 & 2 \\
\hline $80 \mathrm{H}$ & 76 & 5 & 2 & 0 & 17 & 0 \\
\hline $30 \mathrm{P}$ & 59 & 33 & 0 & 0 & 0 & 8 \\
\hline $30 \mathrm{H}$ & 51 & 0 & 26 & 21 & 2 & 0 \\
\hline
\end{tabular}

To assess the accessibility and strength of acid sites in hierarchical HZSM-5, FTIR spectroscopy of adsorbed probe molecules with different basicity and steric hindrance was used. Initially, $\mathrm{CO}$ was used as probe molecules owing to its weak basicity which allows for discrimination of acid sites with different strength, in fact the adsorption of $\mathrm{CO}$ at $80 \mathrm{~K}$ produces a shift of the bands of the hydroxyls $\left(\Delta \mathrm{V}_{\mathrm{OH}}\right)$ forming $\mathrm{OH} \cdots \mathrm{CO}$ hydrogenbonded adducts with the acid sites, the value of the shift has been used to estimate the acidity. ${ }^{[0-42]}$

In Fig. 6 the FTIR spectra of adsorbed $\mathrm{CO}$ at $80 \mathrm{~K}$ on $80 \mathrm{P}$ and $80 \mathrm{H}$ (Fig.6A) and 30P and 30H (Fig.6B) catalysts are reported. Upon $\mathrm{CO}$ interaction at low temperature, the band due to $\mathrm{Si}(\mathrm{OH}) \mathrm{Al}$ Brønsted acid sites $\left(3615 \mathrm{~cm}^{-1}\right)$ present in all catalysts is shifted downward, forming a broad and intense absorption centred at ca. $3300 \mathrm{~cm}^{-1}$ due to the $\mathrm{OH} \cdots \mathrm{CO} \mathrm{H}$-bonded adducts. The frequency shift $\left(\Delta \mathrm{V}_{\mathrm{OH}}\right)$ was about $315 \mathrm{~cm}^{-1}$, typical of microporous HZSM-5 zeolite, ${ }^{[42,43]}$ hence indicating that the acid strength of the Brønsted sites is not affected by the desilication treatment. Increasing the CO coverage, a broad signal centred at ca. $3465 \mathrm{~cm}^{-1}$ appears together with the disappearance of $3665 \mathrm{~cm}^{-1}$ band due to the stretching mode of extraframework $\mathrm{Al}-\mathrm{OH}$ species. This signal is particularly evident in 30P sample (Fig.6B) where the presence of a higher fraction of these Al sites was evidenced by FTIR coupled with ${ }^{1} \mathrm{H}$ MAS NMR. In this case, the frequency shift is ca. $190 \mathrm{~cm}^{-1}$ meaning that the acid strength is lower than Brønsted sites. At higher $\mathrm{CO}$ coverage, 80P shows two negative bands at $3745 \mathrm{~cm}^{-1}\left(\mathrm{SiOH}_{\mathrm{ext}}\right)$ and $3710 \mathrm{~cm}^{-1}$ $\left(\mathrm{SiOH}_{\text {int }}\right)$ and in parallel, two broad signals grow at $3650 \mathrm{~cm}^{-1}$, due to $\mathrm{CO}$ adsorbed on $\mathrm{Si}-\mathrm{OH}_{\mathrm{ext}}\left(\Delta \mathrm{v}_{\mathrm{OH}}\right.$ of $\left.95 \mathrm{~cm}^{-1}\right)$ and $3590 \mathrm{~cm}^{-1}$, due to $\mathrm{CO}$ adsorbed on $\mathrm{SiOH}_{\text {int }}\left(\Delta \mathrm{v}_{\mathrm{OH}}\right.$ of $\left.120 \mathrm{~cm}^{-1}\right) \cdot{ }^{[43]}$ The values of the shift induced by $\mathrm{CO}$ on the $\mathrm{O}-\mathrm{H}$ stretching mode are reported in Table S1 in the SI. In the hierarchical catalysts $(80 \mathrm{H}$ and $30 \mathrm{H})$, the band at $3590 \mathrm{~cm}^{-1}$ is less evident due to the higher contribution of external $\mathrm{Si}-\mathrm{OH}$ produced by desilication. In the case of $30 \mathrm{P}$ samples no band at $3650 \mathrm{~cm}^{-1}$ is detected possibly due to the low quantity of silanols present in this sample, together with the overlapping of positive and negative contributions. In the C-O stretching region, at low CO coverage
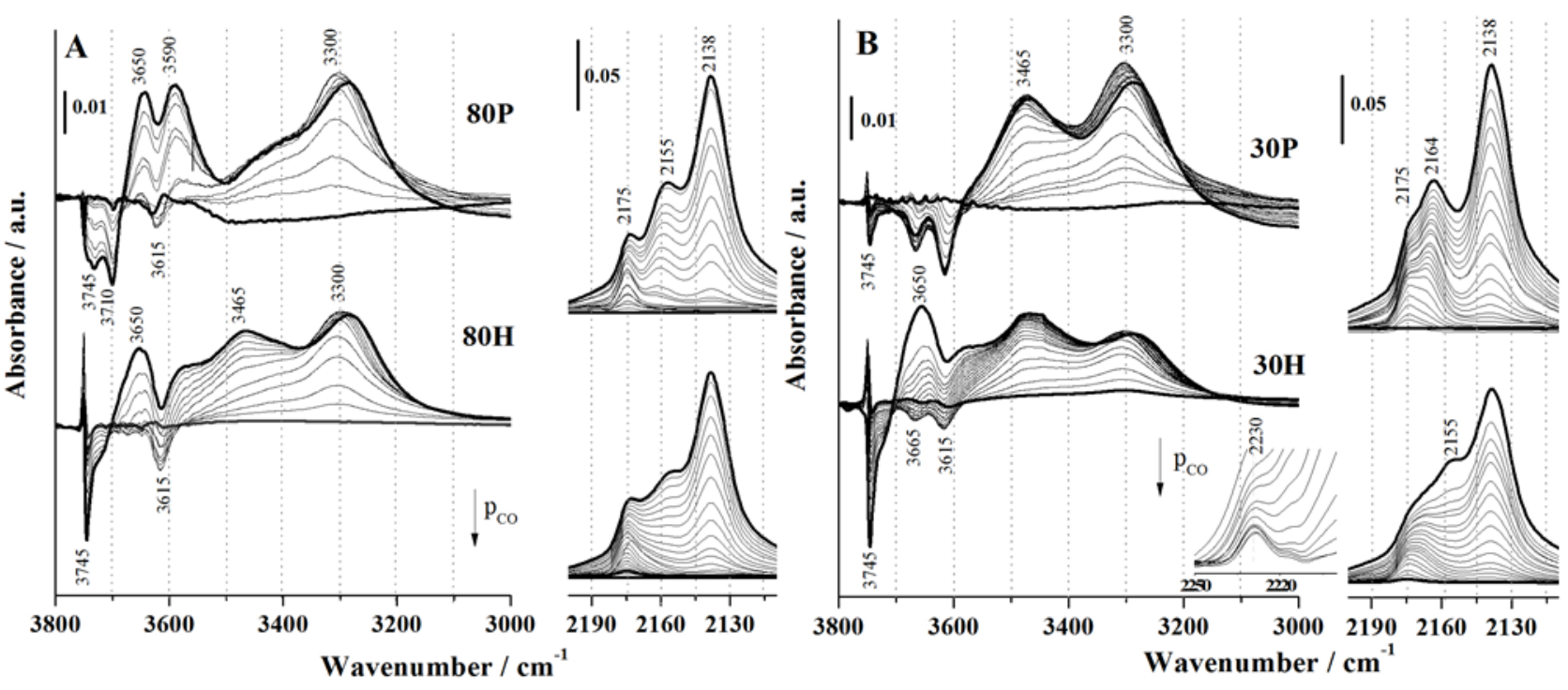

Figure 6. FTIR difference spectra in the $\mathrm{O}-\mathrm{H}$ (left panel) and $\mathrm{C}-\mathrm{O}$ (right panel) stretching region of $\mathrm{CO}$ adsorption at $80 \mathrm{~K}$ on calcined $80 \mathrm{P}$ and $80 \mathrm{H}$ (Section A) and on calcined $30 \mathrm{P}$ and $30 \mathrm{H}$ (Section B) catalysts. 
a signal centred at $2175 \mathrm{~cm}^{-1}$, due to the stretching mode of $\mathrm{CO}$ interacting with Brønsted acid sites, is present in all spectra, although with different intensity. The blue shift observed (36 $\mathrm{cm}^{-1}$ ) with respect to the stretching mode of the free $\mathrm{CO}$ molecule ( $v_{c o}$ liquid-like at $2138 \mathrm{~cm}^{-1}$ ) is similar in all samples due to their similar acid strength. At higher CO pressure, two different behaviours are present. Spectra relative to $80 \mathrm{P}, 80 \mathrm{H}$ and $30 \mathrm{H}$ samples show a signal, centred at $2155 \mathrm{~cm}^{-1}$, ascribed to the stretching mode of $\mathrm{CO}$ interacting with silanols. In contrast $30 \mathrm{P}$ spectrum shows a peak centred at $2164 \mathrm{~cm}^{-1}$, that can be attributed to $\mathrm{CO}$ interacting with extraframework $\mathrm{Al}-\mathrm{OH}$ species. In addition, $30 \mathrm{H}$ spectrum shows a weak feature centered at $2230 \mathrm{~cm}^{-1}$, assigned to the stretching modes of $\mathrm{CO}$ coordinating Lewis acid sites (Fig $6 \mathrm{~B}$ inset). It was suggested that $\mathrm{CO}$ extinction coefficient is diminished upon adsorption on Lewis sites. ${ }^{[44]}$ Therefore, even if the intensity of the signal may seem negligible compared with other signal in the spectrum, it might not have a direct implication on the actual quantity of Lewis sites.

The co adsorption at low temperature illustrated that the strength of the Brønsted sites in the hierarchical catalysts was not affected by the alkaline treatment, however the population of $\mathrm{SiOH}$ was greatly changed and the presence of Lewis sites is noticeable. Nevertheless, given its size, $\mathrm{CO}$ was not able to discriminate the sites based on their location within the hierarchical materials; to better discriminate between the acid sites located inside the micropores and those present on the mesopores surface, the use of larger basic probe was required. Substituted pyridines have been widely used to study and quantify the enhanced accessibility of acid sites in hierarchical zeolites, given their impediment to diffuse through small micropores. ${ }^{[26,45-47]}$. In particular, 2,4,6-trimethilpyridine (2,4,6TMP) with a kinetic diameter ca. $0.74 \mathrm{~nm}$ is too bulky to enter the HZSM-5 micropores and reacts only with the acid sites located in either mesopores or micropore mouths of the hierarchical zeolites. These interactions can be readily identified in the aromatic ring vibration region of the FTIR spectrum. In addition, due to its basicity ( $\mathrm{pKa}=7.59$ ), when the molecule interacts with the Brønsted acid sites in zeolites, a proton transfer occurs and a protonated species $\left(2,4,6-\mathrm{TMPH}^{+}\right)$is formed. In Scheme 1, the IR active modes of the ring both for liquid and adsorbed 2,4,6-TMP on different $\mathrm{OH}$ sites and on Lewis acid centres are highlighted, ${ }^{[46-49]}$ In particular, the $v_{8 a}$

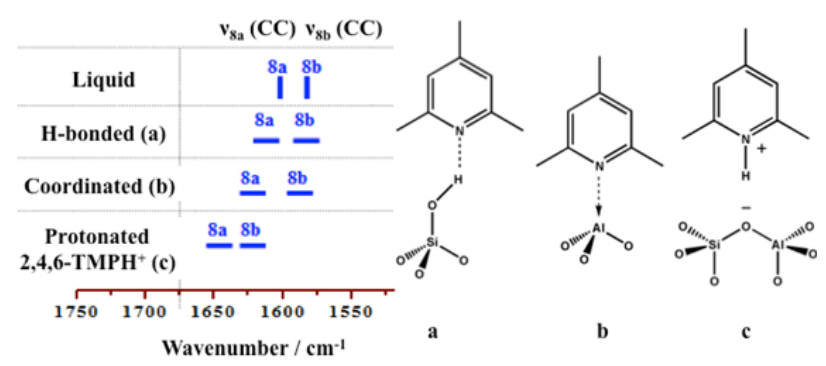

Scheme 1. IR active mode highlighting the different types of 2,4,6$\mathrm{TMP} /$ surface interactions with the catalysts. mode, which in the liquid phase appears at $1611 \mathrm{~cm}^{-1}$, is very sensitive to the acidity of the $\mathrm{OH}$ sites present on the catalysts and its position changes with respect to the strength of the acid centres. In fact, when the $\mathrm{v}_{8 \mathrm{a}}$ appears at wavenumber higher than $1630 \mathrm{~cm}^{-1}$, this can be associated with the formation of a protonated species $\left(2,4,6-\mathrm{TMPH}^{+}\right)$, whereas lower wavenumbers correspond to $\mathrm{H}$-bonded adducts. ${ }^{[46,50-52]}$

2,4,6-trimethylpyridine was adsorbed both on parent and hierarchical HZSM-5 catalysts at room temperature and subsequently desorbed at higher temperature. Fig. 7 shows the FTIR spectra in the stretching region of $\mathrm{C}-\mathrm{C}$ ring vibrations of the 2,4,6-TMP irreversibly adsorbed at room temperature; the spectra are obtained after outgassing the samples for 90 minutes to eliminate the weakly adsorbed species, and after 2,4,6-TMP desorption at higher temperatures. In all samples, bands at 1618 and $1572 \mathrm{~cm}^{-1}$, although with different intensity, typical of 2,4,6-TMP $\mathrm{H}$-bounded to $\mathrm{Si}-\mathrm{OH}$ groups are present. These bands almost completely disappeared after outgassing the samples at $423 \mathrm{~K}$. A band at $1638 \mathrm{~cm}^{-1}$, negligible for the parent zeolites and more resistant to the thermal treatment at higher temperatures, is evident in the hierarchical zeolites and is due to the protonated 2,4,6-TMP molecules $\left(2,4,6-\mathrm{TMPH}^{+}\right)$ formed upon interaction with strong Brønsted acid sites. The presence of this band in the hierarchical catalysts evidenced that desilication enhances the accessibility to the internal Brønsted acid sites. The intensity of the bands due to the collidine irreversibly adsorbed at room temperature is highest in the case of $80 \mathrm{H}$ catalyst suggesting that a higher fraction of Brønsted acid active sites is available.

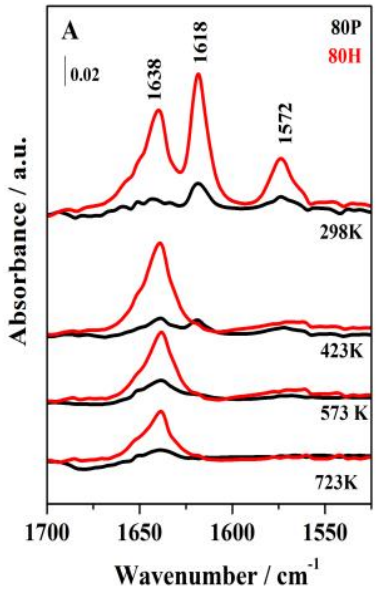

Wavenumber $/ \mathrm{cm}^{-1}$

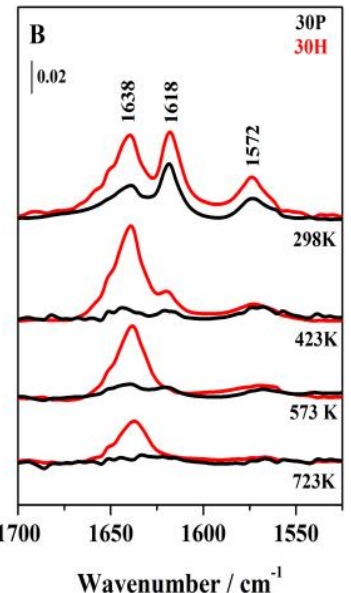

Wavenumber $/ \mathrm{cm}^{-1}$
Figure 7. FTIR difference spectra of $80 \mathrm{P}$ and $80 \mathrm{H}$ (Section $\mathrm{A}$ ) and $30 \mathrm{P}$ and $30 \mathrm{H}$ (Section $\mathrm{B}$ ) upon 2,4,6-TMP outgassing at room temperature (90 $\mathrm{min}$ ) and at higher temperatures (423K, 573K and 723K). 
The total number of accessible Brønsted acid sites $(\mathrm{N})$ has been estimated using the Lambert-Beer law in the form $A=\varepsilon N \rho$ (Table 5); where $A$ is the intensity of the $v_{8 a}\left(1638 \mathrm{~cm}^{-1}\right)$ band (integrated area, $\left.\mathrm{cm}^{-1}\right), \varepsilon$ is the molar extinction coefficient $(\mathrm{cm}$ $\left.\mathrm{mmol}^{-1}\right), \mathrm{N}$ is the concentration of the vibrating species $\left(\mathrm{mmol} \mathrm{g}^{-1}\right)$ and $\rho$ is the density of the disk (mass/area ratio of the pellet, $\mathrm{mg} \mathrm{cm}^{-2}$ ). For the calculations, a value of $0.62 \mathrm{~cm} \mathrm{mmol}^{-1}$ was used for $\varepsilon .{ }^{[47]}$ The data in table 5 clearly show that in the hierarchical materials $(80 \mathrm{H}$ and $30 \mathrm{H})$ the number of the accessible Brønsted sites accessible by molecules as bulky as 2,4,6-TMP is greatly increased with respect to the parent zeolites. Furthermore, it is particularly noteworthy that in the hierarchical materials, the $80 \mathrm{H}$ catalyst possesses a significantly greater fraction of accessible Brønsted sites. The enhanced accessibility of Brønsted sites in $80 \mathrm{H}$ and $30 \mathrm{H}$ hierarchical samples can be directly correlated with their catalytic performance.

Table 5. Integrated area $(A)$ of the $v_{8 a}\left(1638 \mathrm{~cm}^{-1}\right)$ band and concentration of accessible Brønsted sites (N)

\begin{tabular}{ccc}
\hline Catalysts & $\mathrm{A}^{*} / \mathrm{cm}^{-1}$ & $\mathrm{~N} / \mathrm{mmol} \mathrm{g}^{-1}$ \\
\hline $80 \mathrm{H}$ & 1.35 & 2.18 \\
$30 \mathrm{H}$ & 1.04 & 1.69 \\
$80 \mathrm{P}$ & 0.2 & 0.32 \\
$30 \mathrm{P}$ & 0.07 & 0.11 \\
\hline
\end{tabular}

*The integrated area $A$ of the $1638 \mathrm{~cm}^{-1}$ band was obtained using the spectra of the catalysts outgassed at $423 \mathrm{~K}$, to eliminate the contribution of 2,4,6-TMP interacting with Si-OH.

The alkaline treated materials were catalytically evaluated in the liquid-phase Beckmann rearrangement of cyclohexanone oxime to $\varepsilon$-caprolactam (precursor of Nylon-6) at $130^{\circ} \mathrm{C}$, and their performance were contrasted with their analogous parent microporous counterparts. The conversion, yield and selectivity are reported after $7 \mathrm{~h}$ (Fig. S5 in the SI). A blank experiment without the zeolite was also performed (Fig. S6 in the SI). Both hierarchical $80 \mathrm{H}$ and $30 \mathrm{H}$ materials showed superior catalytic performance, in terms of overall conversion and yield towards the desired $\varepsilon$-caprolactam with respect to the parent zeolites (Fig 8). Among the samples tested, the $80 \mathrm{H}$ catalyst showed a significant improvement in overall catalytic activity, with a selectivity, which mirrors that of its parent, microporous analogue $(80 \mathrm{P})$, resulting in enhanced $\varepsilon$-caprolactam production. The $30 \mathrm{H}$ catalyst also displayed enhanced selectivity with respect to the parent zeolite. The catalytic performances are largely retained after two recycles (the conversion was around $70 \%$ in both cycles), thereby vindicating their stability. In addition, by comparing samples with the similar Si/Al ratio, 30P and $80 \mathrm{H}$ ( $\mathrm{Si} / \mathrm{Al}$ ratio 21 and 18 respectively), it is possible to confirm that the higher catalytic conversion and selectivity observed for the hierarchical zeolite $(80 \mathrm{H})$ is due to the increased accessibility of the active sites through the interconnected porous network.
The enhanced catalytic performance observed in the hierarchical zeolites is the result of two concomitant factors: creating a hierarchical architecture through the introduction of interconnected pore networks helps to overcome the diffusion problems and mass-transfer limitations that are present in the conventional microporous catalysts and the tunability of the precise nature and strength of the acid sites for the Beckmann rearrangement for ensuring high catalytic performances. In fact, the loss of Brønsted acid sites upon the alkaline treatment is compensated by the increased accessibility of the active sites.
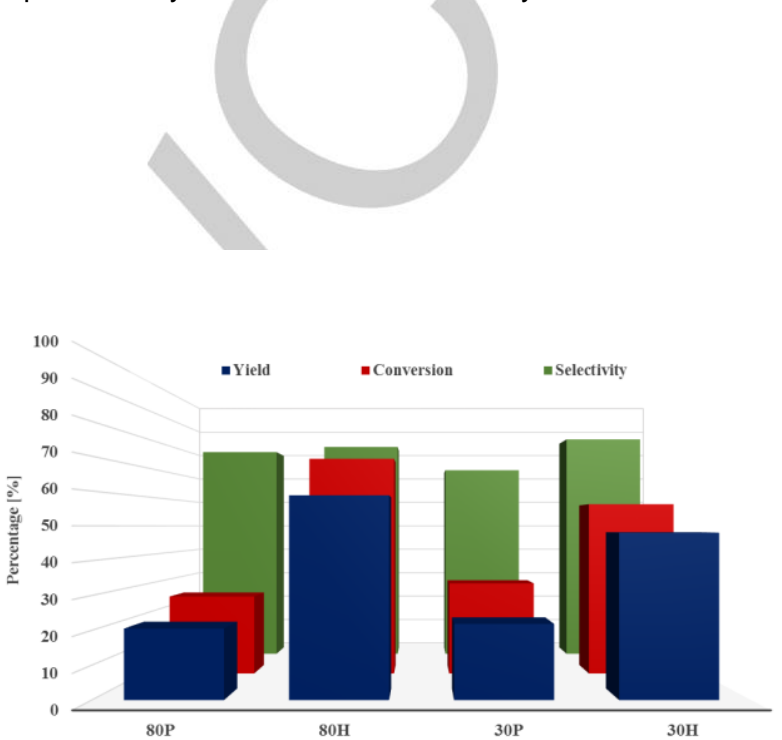

Figure 8. Catalytic activity of hierarchical $(80 \mathrm{H}$ and $30 \mathrm{H})$ and parent (80P and 30P) $\mathrm{H}-\mathrm{ZSM}-5$ after $7 \mathrm{~h}$ at $130{ }^{\circ} \mathrm{C}$ in the liquid-phase Beckmann rearrangement.

\section{Conclusions}

The interplay between the enhanced accessibility of acid sites coupled with the porosity evolution in the production of hierarchical H-ZSM-5 catalysts significantly influences the catalytic performance in the liquid-phase Beckmann rearrangement of cyclohexanone oxime. The desilication methodology crucially impacts the accessibility of the Brønsted sites without altering their strength; though in the hierarchical catalysts, a fraction of Brønsted sites is removed and high fraction of Lewis Al sites (EFAl) is detected both by FTIR and MAS-NMR analyses. The presence of silanol nests, particularly abundant in the HZSM-5 with high Si/AI ratio was also found in all catalysts. The hierarchical H-ZSM- 5 zeolites demonstrated significant enhancement in catalytic activity for the liquid-phase Beckmann rearrangement of cyclohexanone oxime to $\varepsilon$ caprolactam, an important acid-catalyzed industrial reaction, with respect to the microporous parent zeolites. This superior catalytic activity can be rationalized on the basis of the enhanced diffusion, via the interconnected hierarchical network (which was well documented by the volumetric analysis), and to the retention and modulation of the nature and strength of the 
active sites (Brønsted acids and silanol nests) of the parent microporous catalysts. This synergistic interplay enhances both conversion and selectivity in the low-temperature liquid-phase Beckmann rearrangement.

\section{Experimental Section}

\section{Materials}

Commercial $\mathrm{NH}_{4}$-ZSM-5 zeolites were supplied by Zeolyst International with $\mathrm{SiO} 2 / \mathrm{Al}_{2} \mathrm{O}_{3}$ ratio of 30 (CBV 3024E) and 80 (CBV 8014). After being converted to the protonated forms, through calcination at $550{ }^{\circ} \mathrm{C}$ for $16 \mathrm{~h}$ under airflow, the materials were used as parent samples (labelled as 30P and 80P). The parent samples were treated, with different time of contact, in a $0.2 \mathrm{M} \mathrm{NaOH}$ solution (solid/liquid ratio $=22 \mathrm{~g} / \mathrm{L}$ ). Typically, the basic solution was heated in a glass-reactor at $65{ }^{\circ} \mathrm{C}$, under reflux; the catalyst was added and the resulting suspension was treated for the time established; the flask was then cooled down in an ice bath and washed with deionized water until $\mathrm{pH}=7$; the materials obtained was dried overnight, at $60{ }^{\circ} \mathrm{C}$. To convert the hierarchical catalysts into the acidic forms, an ion exchange with a $\mathrm{NH}_{4} \mathrm{NO}_{3}$ solution at $80{ }^{\circ} \mathrm{C}$ was performed (solid/liquid ratio $=6.7 \mathrm{~g} / \mathrm{L}$ ) and finally, the material was calcined in air at $600{ }^{\circ} \mathrm{C}$ for $6 \mathrm{~h}$. The hierarchical materials are labelled $30 \mathrm{H}$ and $80 \mathrm{H}$.

\section{Characterization}

All powder X-ray diffraction patterns were collected using a Bruker D2 diffractometer using $\mathrm{Cu} \mathrm{K} \alpha 1$ radiation. Low-angle $\mathrm{X}$ ray diffraction patterns were obtained using a Bruker $C 2$ GADDS diffractometer. Varian Vista MPX CCD Simultaneous axial instrument was used for ICP-OES analysis. The samples were digested in HF acid $(7.5 \mathrm{mg}$ in $2 \mathrm{ml} \mathrm{HF}$ made up to $100 \mathrm{ml}$ in 18.2 Mohm water). $\mathrm{N}_{2}$ physisorption measurements were carried out at $77 \mathrm{~K}$ in the relative pressure range from $1 \times 10^{-6}$ to $1 \mathrm{P} / \mathrm{P} 0$ by using a Quantachrome Autosorb1MP/TCD instrument. Prior to the analysis, the samples were outgassed at $400 \mathrm{~K}$ for $3 \mathrm{~h}$ (residual pressure lower than $10^{-6}$ Torr). Specific surface areas were determined using the Brunauer-Emmett-Teller equation, in the relative pressure range from 0.01 to $0.1 \mathrm{P} / \mathrm{P}_{0}$. The desorption branch of the $\mathrm{N}_{2}$ physisorption isotherm was analyzed by means of the NLDFT (non-local density functional theory) method, to obtain the pore size distribution of the materials.

Thermogravimetric analyses (TGA/DTG) of materials were performed under argon flow $\left(100 \mathrm{ml} \mathrm{min}^{-1}\right)$ with a SETSYS Evolution TGA-DTA/DSC thermobalance, heating from 40 to $1000^{\circ} \mathrm{C}$ at $5^{\circ} \mathrm{C} \mathrm{min}^{-1}$.

Solid state NMR spectra were acquired on a Bruker Avance III 500 spectrometer and a wide bore 11.7 Tesla magnet with operational frequencies for ${ }^{1} \mathrm{H},{ }^{29} \mathrm{Si}$ and ${ }^{27} \mathrm{Al}$ of $500.13,99.35$ and $130.33 \mathrm{MHz}$, respectively. A $4 \mathrm{~mm}$ triple resonance probe with magic angle spinning (MAS) was employed in all the experiments and the samples were packed on a Zirconia rotor and spun at a MAS rate of $15 \mathrm{kHz}$. The magnitude of radio frequency fields, $v_{\mathrm{rf}}$, were 100 and $42 \mathrm{kHz}$ for ${ }^{1} \mathrm{H}$ and ${ }^{29} \mathrm{Si}$, respectively. The ${ }^{27} \mathrm{Al}$ MAS spectra have been acquired on large sweep width with small pulse angle $(\pi / 12)$ to ensure quantitative interpretation. A rotor synchronized ${ }^{1} \mathrm{H}-{ }^{27} \mathrm{Al}$ TRAPDOR (transfer of populations in double resonance) sequence was applied in order to distinguish the protonic species neighbourhoods. ${ }^{[6]}$ The relaxation delay, d1, between accumulations was $1 \mathrm{~s}$ for ${ }^{27} \mathrm{Al}$ MAS and $120 \mathrm{~s}$ for ${ }^{29} \mathrm{Si}$ MAS NMR as well as $5 \mathrm{~s}$ for ${ }^{1} \mathrm{H}$ MAS NMR. All chemical shifts are reported using $\delta$ scale and are externally referenced to TMS at $0 \mathrm{ppm}$ for ${ }^{1} \mathrm{H} \mathrm{NMR}$ and ${ }^{29} \mathrm{Si}$ $\mathrm{NMR}$ as well as to $\mathrm{Al}\left(\mathrm{H}_{2} \mathrm{O}\right)_{6}{ }^{3+}$ ion in $1.0 \mathrm{M} \mathrm{AlCl}_{3}$ solution at 0.9 ppm for ${ }^{27} \mathrm{Al}$ NMR.

All NMR spectra were fitted with DMFIT functions for quantitative deconvolution of overlapping peaks. ${ }^{[53]}$ The samples were packed on a NMR rotor and dehydrated at $250{ }^{\circ} \mathrm{C}$ under vacuum $\left(1 \times 10^{-3} \mathrm{mbar}\right)$ for $2 \mathrm{~h}$ prior to the loading into the magnet and recorded the NMR spectrum.

FTIR spectra of self-supporting pellets in proton form were collected under vacuum conditions (residual pressure $<10-5$ Torr) using a Bruker Equinox 55 spectrometer equipped with a pyroelectric detector (DTGS type) with a resolution of $4 \mathrm{~cm}^{-1}$. All samples were re-calcined at $823 \mathrm{~K}$ in oxygen to remove any possible organic contaminants before the FTIR experiments. CO was adsorbed at $80 \mathrm{~K}$ and 2,4,6-trimethylpyridine (collidine) was adsorbed at room temperature on the calcined samples, using specially designed cells permanently connected to a vacuum line to perform adsorption-desorption in situ measurements. FTIR spectra were normalized with respect the pellet weight and whenever specified, are reported in difference mode by subtracting the spectrum of the sample in vacuum to the spectrum of the adsorbed molecules ( $\mathrm{CO}$ and collidine).

\section{Catalysis}

For testing the materials in the liquid phase Beckmann rearrangements, $0.1 \mathrm{~g}$ of the catalyst, $100 \mathrm{mg}$ of cyclohexanone oxime and $0.1 \mathrm{~g}$ of chlorobenzene (internal standard) were weighed in a glass-reactor; $20 \mathrm{~mL}$ of benzonitrile anhydrous were added and the temperature was raised up to $130{ }^{\circ} \mathrm{C}$. The reaction was carried out for $7 \mathrm{~h}$ under nitrogen flux. Samples were analyzed periodically, using a Clarus 480 gas chromatograph with FID detector with an Elite 5 column. Products were identified against authenticated standards and quantified by calibration to obtain response factors (RF) against the known internal standard. Afterwards, the reaction mixture was filtered and the filtrate (catalyst) was washed with $300 \mathrm{~mL}$ of ethanol. The recovered catalyst was then calcined at $600^{\circ} \mathrm{C}$ and tested for the second catalytic cycle, under the same conditions described above. 


\section{Acknowledgements}

This research is supported by the Compagnia di San Paolo (HEPYCHEM project). The UK Catalysis Hub funded by EPSRC (Engineering and Physical Sciences Research Council) via grants EP/K014706/1, EP/K014668/1, EP/K014854/1, $\mathrm{EP} / \mathrm{K} 014714 / 1$ and EP/M013219/1. SHN acknowledges Honeywell LLC for studentship funding.

Keywords: Hierarchical zeolites • Beckmann rearrangement • Catalytic diffusion $\cdot$ Spectroscopic characterization $\bullet$ Probe molecules

[1] M. Hartmann, Angew. Chem. Int. Ed. 2004, 43, 5880-5882.

[2] S. Mitchell, B. Pinar, J. Kenvin, P. Crivelli, J. Kärger, J. Pérez-Ramírez, Nat. Commun. 2015, 6:8633 doi: 10.1038/ncomms9633.

[3] C.M.A. Parlett, K. Wilson, A.F. Lee, Chem. Soc. Rev. 2013, 42, 3876 3893;

[4] K. Li, J. Valla, J. Garcia-Martinez, ChemCatChem 2014, 6, 46-66

[5] J. Shi, Y. Wang, W. Yang, Y. Tang , Z. Xie, Chem. Soc. Rev. 2015, 44 8877- 8903.

[6] J. Pérez-Ramírez, C. H.Christensen, K. Egeblad, C. H. Christensen, J. C. Groen, Chem. Soc. Rev. 2008, 37, 2530-2542.

[7] K. Möller, T. Bein, Chem. Soc. Rev. 2013, 42, 3689-3707.

[8] D. P. Serrano, J. M. Escola, P. Pizarro, Chem. Soc. Rev. 2013, 42, 4004 4035.

[9] W. Schwieger, A. Gonche Machoke, T. Weissenberger, A. Inayat, T. Selvam, M. Klumpp, A. Inayat, Chem. Soc. Rev. 2016, 45, 3353-3376.

[10] a) I.I Ivanova, E.E. Knyazeva, Chem. Soc. Rev. 2013, 42, 3671-3688. b) I.I. Ivanova, I.A. Kasyazeva, A.A. Maerle, V.I. Zaikovskii, Micropor. Mesopor. Mater. 2014, 189, 163-172.

[11] D. Verboekend, J. Pérez-Ramírez, Catal. Sci. Technol. 2011, 1, 879890.

[12] J. Pérez-Ramírez, S. Mitchell, D. Verboekend, M. Milina, N-L. Michels, F. Krumeich, N. Marti, M. Erdmann, ChemCatChem 2011, 3, 1731-1734.

[13] J. C. Groen, T. Bach, U. Ziese, A. M. Paulaime-van Donk, K. P. de Jong J. A. Moulijn and J. Pérez-Ramírez, J. Am. Chem. Soc. 2005, 127, 10792-10793.

[14] J. C. Groen, W. Zhu, S. Brouwer, S. J. Huynink, F. Kapteijn, J. A. Moulijn, J. Pérez-Ramírez, J. Am. Chem. Soc. 2007, 129, 355-360.

[15] D. A. Young, US patent US3326797, 1967.

[16] M. Ogura, S. Y. Shinomiya, J. Tateno, Y. Nara, E. Kikuchi, H. Matsukata, Chem. Lett. 2000, 8, 882-883

[17] J. C. Groen, L. A. A. Peffer, J. A. Moulijn, J. Pérez-Ramírez, Micropor Mesopor. Mater. 2004, 69, 29-34.

[18] Y. Yan, X. Guo, Y. Zhang, Y. Tang, Catal. Sci. Technol. 2015, 5, 772785.

[19] A. Corma, J Catal 2003, 216, 298-312.

[20] K. Tanabe, W.F. Hölderich, Appl. Catal. A: General 1999, 181, 399-434.

[21] M. S. Holm, S. Svelle, F. Joensen, P. Beato, C. H. Christensen, S. Bordiga, M. Bjørgen, Appl. Catal. A: General 2009, 356, 23-30.

[22] K. Goŕa-Marek, K. Tarach,M. Choi, J. Phys. Chem. C 2014, 118, $12266-12274$.

[23] K. Sadowska, K.Goŕa-Marek, J. Datka J. Phys. Chem. C 2013, 117, 9237-9244.
[24] S. H. Newland, R. Raja, A.B. Levy, US Patent 62/092,471 filed Dec 2014

[25] M.A. Camblor, A. Corma, H. Garcia, V.Semmer-Herlédan, S. Valencia J. Catal. 1998, 177, 267-272.

[26] Y. Izumi, H. Ichihashi, Y. Shimazu, M. Kitamura, H. Sato, Bull. Chem. Soc. Jpn. 2007, 80, 1280-1287.

[27] Y. Chu, P. Ji, X. Yi, S. Li, P. Wu, A. Zheng, F. Deng, Catal. Sci. Technol. 2015, 5, 3675-3681.

[28] G.P.Heitmann, G.Dahlhoff, W.F.Hölderich J. Catal. 1999, 186, 12-19.

[29] J. C. Groen, J. A. Moulijn, J. Perez-Ramırez, Ind. Eng. Chem. Res. 2007, 46, 4193-4201.

[30] E. Senderov, I. Halasz, D. H. Olson, Microp. Mesop. Mater. 2014, 186, 94-100.

[31] A.M. Ferrari, E. Garrone, G. Spoto, P. Ugliengo, A. Zecchina, Surface Science 1995, 323, 151-162.

[32] Y. Inaki, H. Yoshida, T.Yoshida, T. Hattori, J. Phys. Chem. B, 2002, 106 9098-9106.

[33] Y. Jiang, J. Huang, W. Dai, M. Hunger, Solid State Nuclear Magnetic Resonance 2011, 39, 116-141.

[34] M. Hunger, S. Ernst, S. Steuernagel, J. Weitkamp, Microporous Mater. 1996, 6, 349-353.

[35] E.J.M. Hensen, D.G. Poduval, V. Degirmenci, D.A J. M. Ligthart, W Chen, F. Mauge, M.S. Rigutto, J.A.R. van Veen, J. Phys. Chem. C 2012 116, 21416-21429.

[36] A. Simon, R. D. Gougeon, J-L. Paillaud, V. Valtchev, H. Kessler, Phys Chem. Chem. Phys. 2001, 3, 867-872.

[37] C. Chizallet and P. Raybaud, Angew. Chem. Int. Ed. 2009, 48, 2891-893.

[38] M.F. Williams, B. Fonfé, C. Sievers, A. Abraham, J.A. van Bokhoven, A Jentys, J.A.R. van Veen, J.A. Lercher, J. Catal. 2007, 251, 485-496.

[39] Z. Yu, A. Zheng, Q. Wang, L. Chen, J. Xu, J.-P. Amoureux, F. Deng Angew. Chem. Int. Ed. 2010, 49, 8657-8661.

[40] M.A.Makarova, A.F. Ojo, K. Karim, M. Hunger, J.J. Dwyer, J. Phys. Chem. 1994, 98, 3619-3623.

[41] H. Knözinger, S.J. Huber, Chem. Soc. Faraday Trans. 1998, 94 2047-2059.,

[42] K. Chakarova, K. Hadjiivanov, J. Phys. Chem. C 2011, 115, 4806 4817.

[43] C. Pazé, S. Bordiga, C. Lamberti, M. Salvalaggio, A. Zecchina, J. Phys. Chem. B 1997, 101, 4740-4751.

[44] F. Wakabayashi, J.N. Kondo, K. Domen, C. Hirose, J. Phys. Chem 1995, 99, 10573-10580

[45] F. Thibault-Starzyk, I. Stan, S. Abellò, A. Bonilla, K. Thomas, C Fernandez, J.-P. Gilson, J. Perez-Ramirez, J. Catal. 2009, 264, 11 14.

[46] F. Thibault-Starzyk, A. Vimont, J-P. Gilson, Catalysis Today 2001 70, 227-241.

[47] K. Mlekodaj, K. Tarach, J. Datka, K. Góra-Marek, W. Makowski, Micropor. Mesopor. Mater. 2014, 183, 54-61.

[48] M. Milina, S. Mitchell, N.-L. Michels, J. Kevin, J. Perez-Ramirez, J. Catal. 2013, 308, 398-407.

[49] J.F. Arenas, I. Lopez Tocon, J.C. Otero, J.I. Marcos, J. Mol. Struct. 1999 476, 139-150

[50] E. Gianotti, M. Manzoli, M.E. Potter, V.N. Shetti, D. Sun, J. Paterson, T.M. Mezza, A. Levy, R. Raja, Chem.Sci. 2014, 5, 1810-1819.

[51] P. A. Jacobs and C. F Heylen, J. Catal. 1974, 34, 267-274

[52] C. Morterra, G. Cerrato and G. Meligrana, Langmuir, 2001, 17, 70537060 .

[53] D. Massiot, F. Fayon, M. Capron, I. King, S. Le Calve, B. Alonso, J.-O Durand, B. Bujoli, Z. Gan, G. Hoatson, Magn. Reson. Chem. 2002, 40, 70-76. 


\section{FULL PAPER}

Hierarchically-porous architectures highly active and selective for low temperature acid catalysis

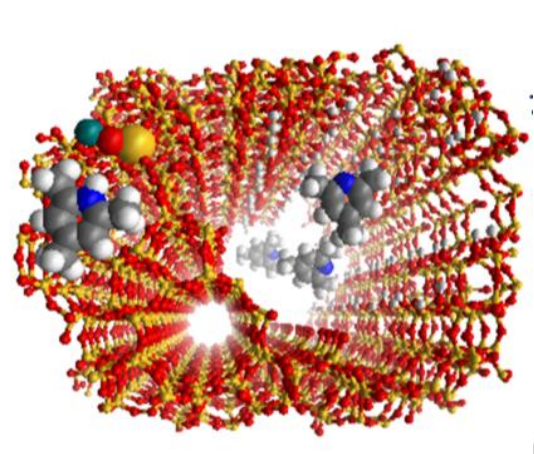

Andrea Erigoni, Stephanie H. Newland, Geo Paul, Leonardo Marchese, Robert Raja and Enrica Gianotti

Page No. - Page No.

Creating accessible active sites in hierarchical MFI zeolites for lowtemperature acid catalysis 


\section{Supporting Informations}

Creating accessible active sites in hierarchical MFI zeolites for low-temperature acid catalysis Andrea Erigoni $^{\mathrm{a}}$, Stephanie H. Newland ${ }^{\mathrm{b}}$, Geo Paul ${ }^{\mathrm{a}}$, Robert Raja ${ }^{\mathrm{b}}$, Leonardo Marchese ${ }^{\mathrm{a}}$, Enrica Gianotti $^{\mathrm{a}^{*}}$

${ }^{a}$ Department of Science and Technological Innovation and Nano-SiSTeMI Centre, Università del Piemonte Orientale, Viale T. Michel 11, 15121 Alessandria, Italy.

${ }^{b}$ School of Chemistry, Faculty of Natural and Environmental Sciences, University of Southampton, Southampton SO17 1BJ, UK

\section{*Corresponding authors}

enrica.gianotti@uniupo.it

\section{$\underline{\text { Table of contents }}$}

Fig.S1

Page S2

Fig. S2

Page S2

Fig. S3

Page S3

Fig.S4

Page S4

Fig.S5

Page S5

Fig.S6

Page S5

Fig.S7

Page S6

Table S1

Page S6 


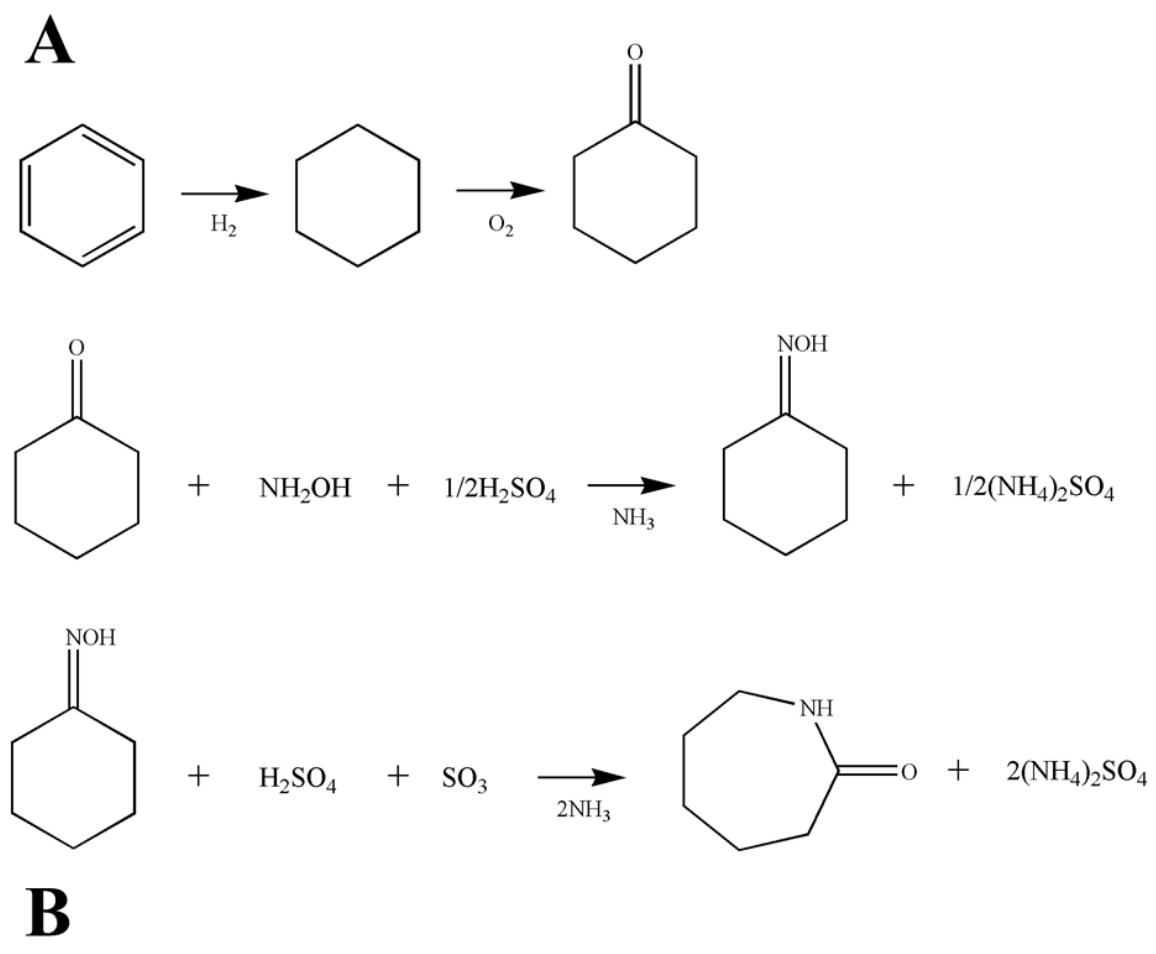

$+\mathrm{H}_{2} \mathrm{O}_{2}+\mathrm{NH}_{3} \underset{\mathrm{TS}-1}{\longrightarrow}+2 \mathrm{H}_{2} \mathrm{O}$<smiles>N=C1NCCCCCC1=O</smiles>

Figure S1_A: Raschig process for $\varepsilon$-caprolactam (homogeneous catalysis). B: Sumitomo Chemical Co. process

A<smiles>O=[N+](O)O[Si](=O)(=O)O</smiles>

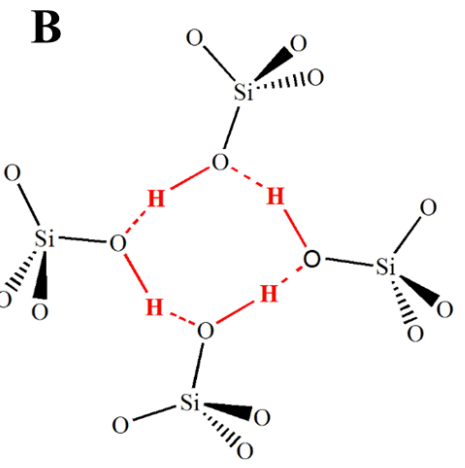

Figure S2: Schematic representation of Brønsted acid sites (A) and nest silanols (B) 


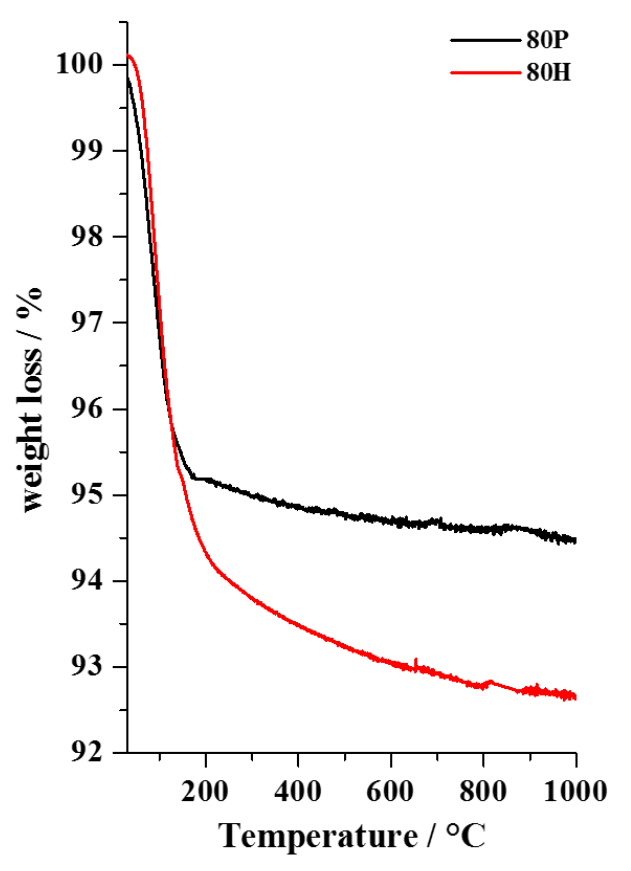

Figure S3: Thermogravimetric analysis of $80 \mathrm{P}$ (black curve) and $80 \mathrm{H}$ (red curve) samples from $25^{\circ} \mathrm{C}$ to $1000{ }^{\circ} \mathrm{C}$. 


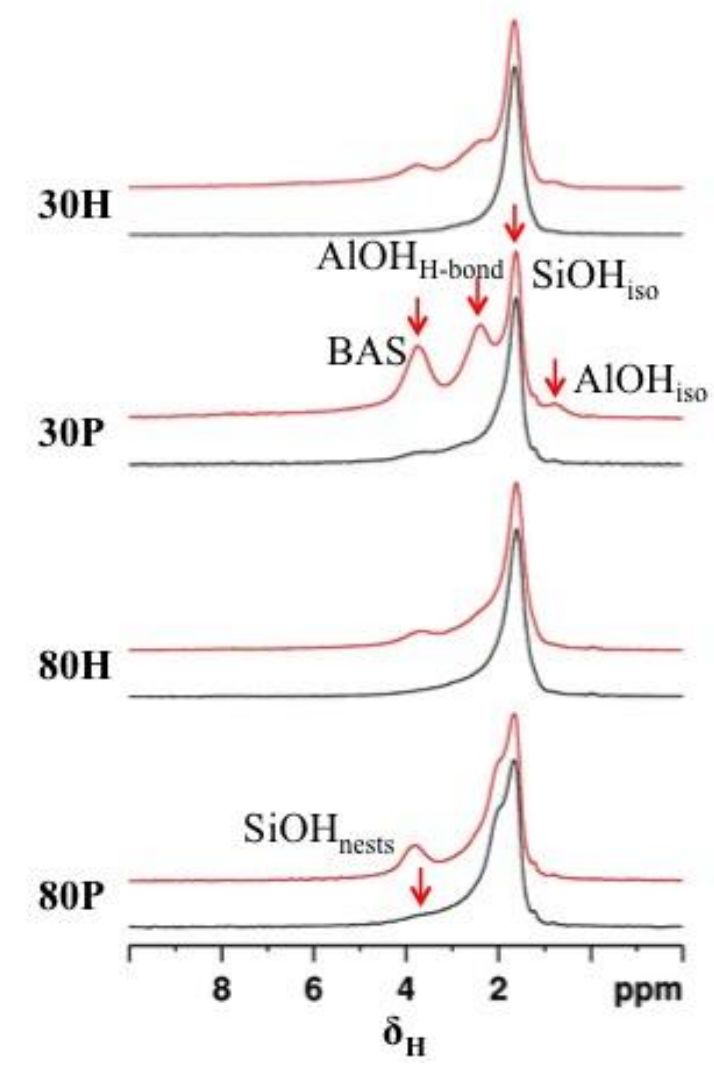

Figure S4: Spin echo ${ }^{1} \mathrm{H}$ MAS NMR spectra of samples recorded without (red) and with (black) ${ }^{27} \mathrm{Al}$ irradiation during pulse delay $\tau$. 


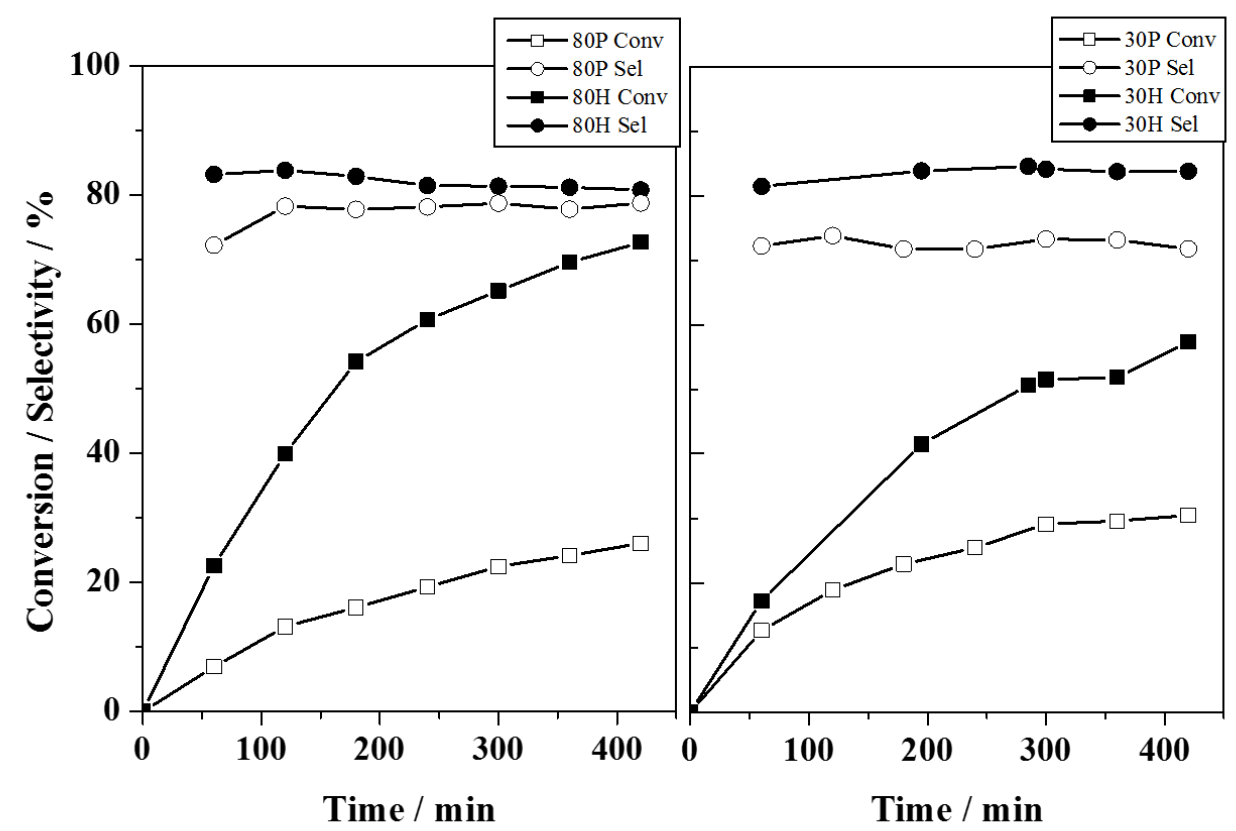

Figure S5: Conversion of cyclohexanone oxime (circles) and selectivity toward caprolactam (squares) at different times of reaction. Solv: benzonitrile; T: $130{ }^{\circ} \mathrm{C}$; catalysts: $80 \mathrm{P}$ and $30 \mathrm{P}$ (white markers), $80 \mathrm{H}$ and $30 \mathrm{H}$ (black markers).

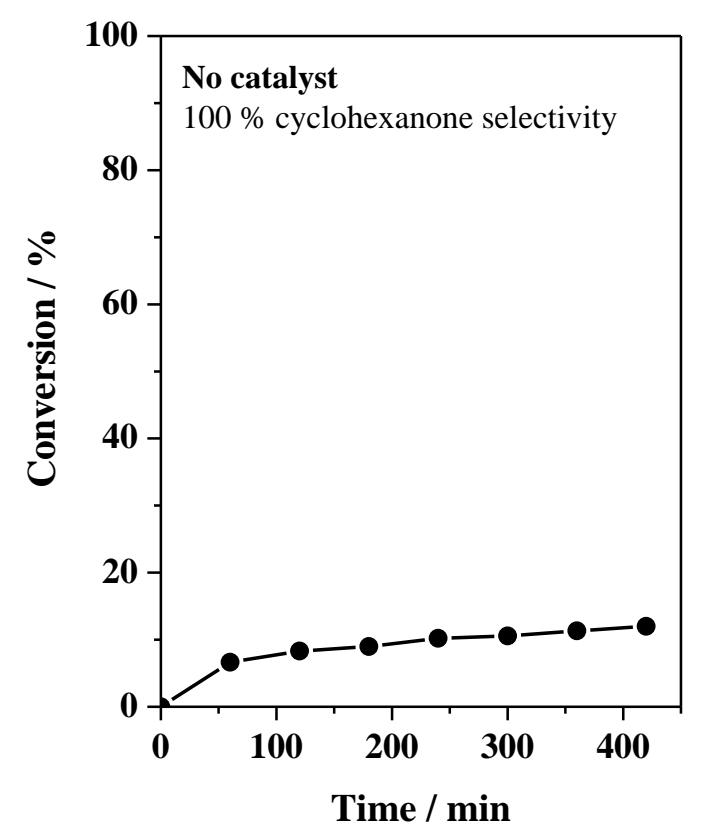

Figure S6: Conversion of cyclohexanone oxime without the catalyst at different times of reaction. Solv: benzonitrile; $\mathrm{T}$ : $130{ }^{\circ} \mathrm{C}$. 


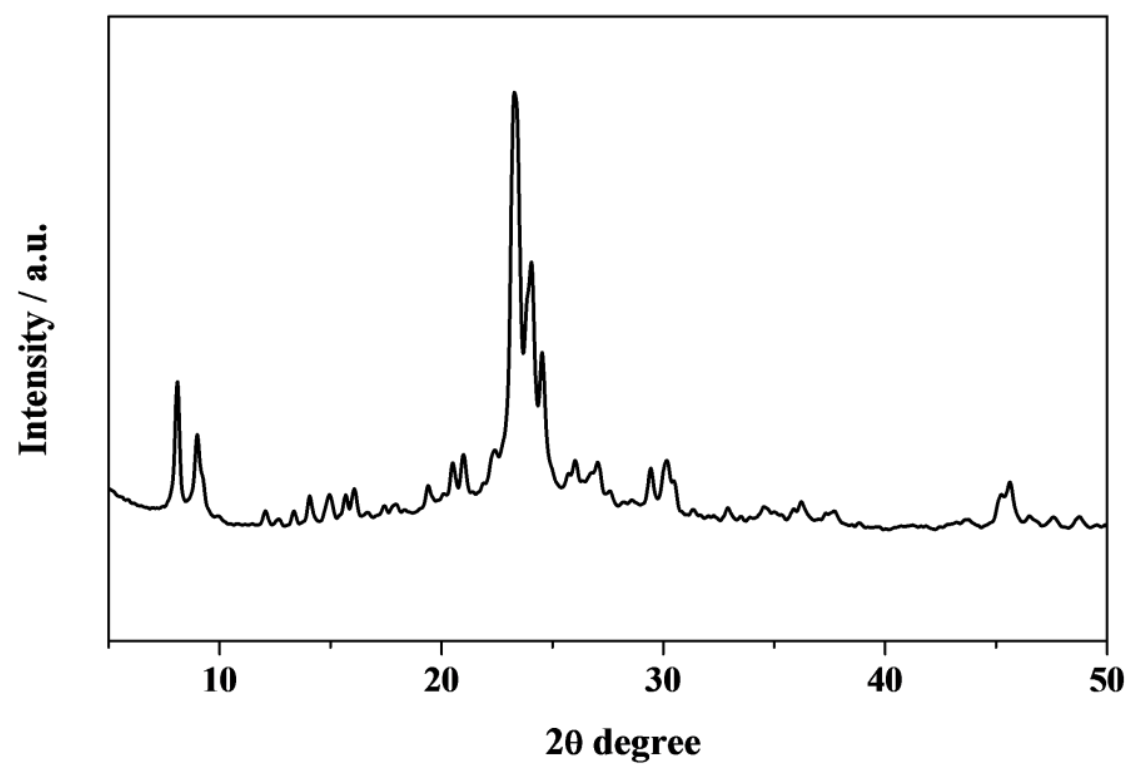

Figure S7: XRD pattern of $30 \mathrm{H}$ zeolite after one catalytic cycle.

Table S1- CO induced shift of the O-H stretching mode.

\begin{tabular}{|c|c|c|c|}
\hline Type of OH groups & v OH $/ \mathrm{cm}^{-1}$ & v OH....CO / $\mathrm{cm}^{-1}$ & $\Delta v \mathrm{OH} / \mathrm{cm}^{-1}$ \\
\hline Si-OH-AI (BAS) & 3615 & 3300 & 315 \\
\hline Al-OH & 3665 & 3465 & 190 \\
\hline Si-OHint & 3710 & 3590 & 120 \\
\hline Si-OHext & 3745 & 3650 & 95 \\
\hline
\end{tabular}

